\title{
Politicas Públicas: Uma Análise dos Indicadores de Desempenho dos Gastos Públicos em Educação Básica nos Municípios do Cariri Ocidental da Paraíba ${ }^{1}$
}

\author{
Public Policy: A Performance Indicators Analysis of Public \\ Expenditure on Basic Education in Municipalities of the Western \\ Cariri of Paraíba
}

\section{Políticas Públicas: Un Indicadores de Desempeño Análisis de Gasto Público en Educación Básica en Municipios de la Cariri Occidental de Paraiba}

\author{
Valquiria Braz Tavares \\ Graduanda em Tecnologia em Gestão Pública \\ Universidade Federal de Campina Grande \\ Endereço: Francisco Duarte, 113, Centro, Sumé, PB, \\ CEP: 58.540-000, Fone: (83) 99804-1265 \\ e-mail: valquiriabtavares@gmail.com
}

\author{
José Fagner Barbosa Alves \\ Graduanda em Tecnologia em Gestão Pública \\ Universidade Federal de Campina Grande \\ Endereço: Rua do Sesquicentenario, 45, Centro, \\ Camalaú, PB, CEP: 58.530-000
}

Fone: (83) 99603-0181, e-mail: fagner.jf2@gmail.com

\section{RESUMO}

Este trabalho objetiva analisar a evolução dos indicadores de desempenho dos gastos públicos em educação básica nos municípios do Cariri Ocidental da Paraíba no período de 2007 a 2011. Foi realizada uma pesquisa descritiva, por meio de análise documental e abordagem quantitativa dos dados, com consulta ao banco de dados do IDGPB Web desenvolvido pelo Tribunal de Contas da Paraíba e Universidade Federal da Paraíba. O universo da pesquisa corresponde aos 17 municípios do Cariri Ocidental da Paraíba. Para análise dos dados utilizou-se ferramentas da estatística descritiva. Os resultados apontam que houve crescimento nas taxas de aprovação, das notas do IDEB e diminuição das taxas de reprovação, de abandono escolar e de distorção idade-série. Ficou constatado que o percentual de alunos que dependem do uso de transporte escolar subiu, representando 27,07\% do alunado. Verificou-se também uma queda de 19,86\% no percentual de docentes com ensino médio/magistério completo e um aumento significativo em relação ao percentual de docentes com formação superior e pósgraduação, representando uma ascensão de 9,34\% e 399,71\% respectivamente. Concluiu-se que no que concerne aos indicadores de desempenho dos gastos públicos em educação básica que a região estudada tende a possuir resultados acima da média do Estado da Paraíba.

Palavras-chave: Indicadores. Educação. Gastos Públicos.

ABSTRACT

This study aims to analyze the evolution of the performance indicators of public spending on basic education in Paraiba of the Western Cariri municipalities from 2007 to 2011. A descriptive study was conducted by means of document analysis and quantitative analysis of the data, in consultation with the IDGPB web database developed by the Court of Paraiba and the Federal University of Paraíba. The research universe corresponds to the 17 municipalities of West Cariri of Paraíba. For data

${ }_{1}^{1}$ Artigo participante e premiado no Fast Track Reunir no IV SIGESP - Simpósio de Instituições e Gestão Pública da UFCG, 2015.

REUNIR: Revista de Administração, Contabilidade e Sustentabilidade ISSN: 2237-3667, Vol. 5, n. 3, p.76-92, 2015 
analysis we used descriptive statistics tools. The results show that there was an increase in approval rates, IDEB notes and decreased failure rates, dropout and age-grade. It was found that the percentage of students who rely on school transportation use rose, representing $27.07 \%$ of the student body. There was also a decrease of $19.86 \%$ in the percentage of teachers with high school / full professorship and a significant increase over the percentage of teachers with higher education and graduate, representing a rise of $9.34 \%$ and $399,71 \%$ respectively. It was concluded that with respect to the performance indicators of public spending on basic education that the study area tends to have results above the Paraiba state average.

Keywords: Indicators. Education. Public spending.

\section{RESUMEN}

Ese trabajo objetiva analizar la evolución de los indicadores de desempeño de los gastos públicos en educación básica en los municipios del Cariri Occidental de la Paraíba, en el período de 2007 a 2011. Fue realizada una pesquisa descriptiva, por medio de análisis documental y abordaje cuantitativo de los dados, con consulta al banco de dados del IDGPB Web desarrollado por el Tribunal de Cuentas de la Paraíba y Universidad Federal de la Paraíba. El universo de la pesquisa corresponde a los 17 municipios del Cariri Occidental de la Paraíba. Para análisis de los dados utilizó se herramientas de la estadística descriptiva. Los resultados apuntan que hube crecimiento en las tasas de aprobación, de las notas del IDEB y diminución de las tasas de reprobación, de abandono escolar y de distorsión edad-serie. Se quedó constatado que el perceptual de alumnos que dependen del uso de transporte escolar subió, representando 27,07\% del alunado. Se verificó, también, una queda de $19,86 \%$ en el perceptual de docentes con enseñanza medialmagisterio completo y un aumento significativo en relación al perceptual de docentes con formación superior y pós-graduación, representando una ascensión de 9,34\% e $399,71 \%$ respectivamente. Se concluye que en lo que concierne a los indicadores de desempeño de los gastos públicos en educación básica que la región estudiada tiende a presentar resultados arriba de la media del "Estado" de la Paraíba.

Palabras clave: Indicadores. Educación. Gastos Públicos.

\section{INTRODUÇÃO}

O momento atual em nosso país é conduzido pelo sentimento de cobrança por serviços públicos que de fato atendam as necessidades dos cidadãos. A sociedade está cada vez mais ciente de que sua contribuição, via tributos, é que move a engrenagem da máquina pública nos seus níveis distintos de governo e passou a pressionar os governantes por melhorias de qualidade de vida. E esse novo momento faz com que os governos trabalhem para traçar novas políticas públicas capazes de satisfazer as demandas sociais.

O objetivo central das políticas públicas é fazer com que os governos ajam, ou seja, coloquem toda sua plataforma eleitoral e as demandas que surgirem eventualmente para de fato atender as necessidades das pessoas, tudo isso por meio de ações que visem impactar de forma positiva. Souza (2006), diz que além de colocar o governo em ação, é preciso que esta ação seja analisada quando necessário para evitar distorções em sua trajetória, e se houver ruptura no caminho traçado nas ações definidas, propor mudanças. No país são várias as áreas de atuação do setor público no que diz respeito às políticas públicas, uma delas é a educação, tema central do atual o Governo Federal.

REUNIR: Revista de Administração, Contabilidade e Sustentabilidade ISSN: 2237-3667, Vol. 5, n. 3, p.76-92, 2015 
De fato, a educação configura-se como sendo a principal ferramenta para o desenvolvimento de uma nação independentemente da sua nacionalidade, idade, raça e cultura (ALAN et al. 2010, apud MACÊDO et al., 2012), uma vez que, no entendimento de Self e Grabowski (2003, apud MACÊDO et al., 2012) a educação influencia potencialmente o crescimento. Partindo para educação no contexto do setor público, Filho (2008, p.6) diz que: “O envolvimento do Estado na educação certamente tem outras importantes justificativas como, por exemplo, a necessidade de investimento no "capital humano", a educação gratuita no contexto da distribuição de renda etc".

Em outras palavras, a opinião dos autores enfatiza a essencialidade da educação em uma sociedade, tanto no aspecto social, quanto no econômico, haja vista sua contribuição para formação de cidadãos conscientes e produtivos, e como educação é algo tão relevante, o Estado certamente deve se envolver de maneira a propiciar investimentos eficientes na área.

Deste modo, diante da relevância evidenciada sobre a educação e buscando verificar o desempenho dos indicadores de desempenho dos gastos públicos em educação básica, eis que emerge o questionamento da pesquisa: Como andam os indicadores de desempenho educacionais no Cariri Ocidental, em relação a toda Paraíba?

Com o intuito de responder a questão de pesquisa, este artigo traçou como objetivo analisar a evolução dos indicadores de desempenho dos gastos públicos em educação básica nos municípios do Cariri Ocidental da Paraíba no período de 2007 a 2011.

A realização deste estudo se deu em função da grande importância das políticas públicas em educação para desenvolvimento de uma região, principalmente quando tais regiões são carentes e dependem de uma maior atenção por parte do setor público, como é o caso da Microrregião do Cariri Ocidental da Paraíba, que pertence a um Estado colocado nas últimas posições em termos de qualidade da educação no País.

\section{REFERENCIAL TEÓRICO}

Nesta serão apresentados alguns aspectos relativos às Políticas Públicas, buscando relacioná-las aos gastos públicos com a educação.

\subsection{Conceito de Políticas Públicas}

A temática das Políticas Públicas apenas recentemente passou a receber um olhar diferenciado, tanto da sociedade, quanto das próprias universidades, que 
passaram à desenvolver trabalhos no intuito de entender e analisar as políticas públicas (NOBREGA JR., 2014). Souza (2006) nos apresenta que inicialmente, as políticas públicas eram tidas como áreas de ações exclusivas do Estado ou governo, mas devido a mudanças nas demandas por parte da população, especialmente a partir dos anos 80, o tema ganhou maior notoriedade, especialmente em países em desenvolvimento.

Não se pode afirmar que exista uma definição universal acerca do tema politicas públicas, entretanto, Souza (2006) afirma que a definição mais conhecida é a de Laswell que afirma que as decisões e análises sobre políticas públicas deve responder à três questões: Quem ganha o quê? Por quê? Que diferença faz? Outros definem o papel da política pública como sendo resolver problemas públicos. De forma geral pode-se afirmar que política pública é o campo do conhecimento que busca, "colocar o governo em ação" e também analisar essa ação. Quando for preciso propor mudanças nas ações. A elaboração de políticas públicas é uma fase onde os governos apresentam suas propostas de mudanças ou os resultados produzidos (SOUZA 2006, p.67).

Existem alguns modelos que buscam explicar como os governos atuam, fazendo ou deixando de fazer alguma ação que possa impactar de forma contundente na vida dos cidadãos. Dentre esses modelos, o Ciclo de Políticas Públicas tem se mostrado um modelo bem interessante por possuir características que permitem que a sequência das etapas constituam um processo dinâmico e que permite o aprendizado em cada uma delas.

A Figura 1 abaixo, nos apresenta um modelo de Ciclo de Políticas Públicas, o que torna de mais fácil compreensão acerca das fases que compõe o ciclo onde a integração das fases resulta na Política Pública.

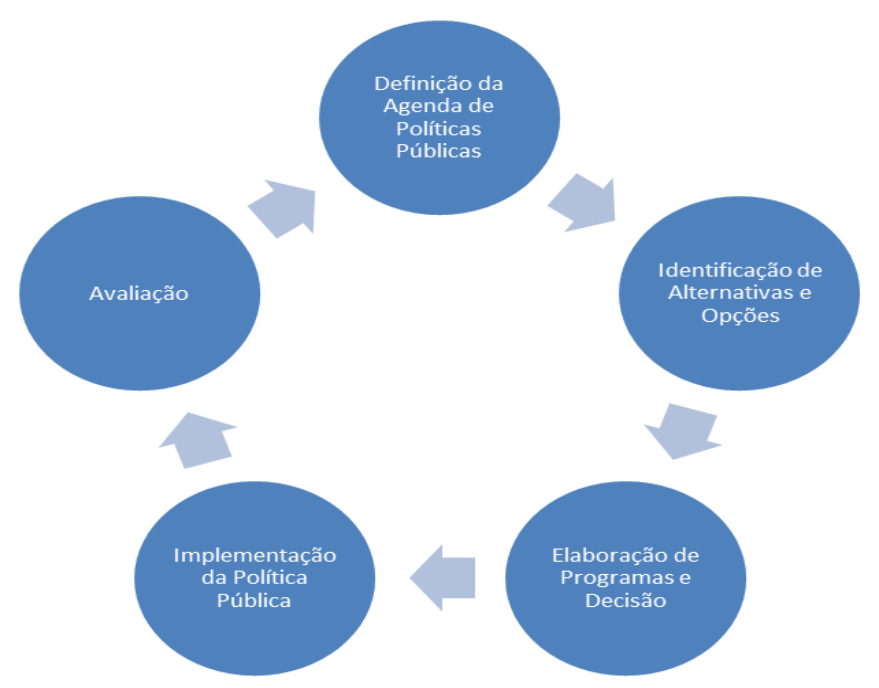

Figura 1 - Ciclo de Políticas Públicas

Fonte: Elaboração dos autores

REUNIR: Revista de Administração, Contabilidade e Sustentabilidade ISSN: 2237-3667, Vol. 5, n. 3, p.76-92, 2015 
A etapa de definição da agenda de políticas públicas é aquela em que são estabelecidas as prioridades em que os governantes deverão focar suas atenções, essa fase é uma das principais do ciclo. Na sequencia, na identificação de alternativas e opções são expostas as alternativas que possam ser aplicadas na resolução dos problemas encontrados na etapa anterior. Na elaboração de programas de decisão é preciso escolher a mais apropriada entre as várias alternativas de ação. Em geral, a instância de decisão responsável decide sobre um programa de compromisso negociado já antecipadamente entre os atores políticos mais relevantes. A implementação de políticas pode ser considerada aquela fase do ciclo cuja encomenda de ação é estipulada na fase precedente à formulação das políticas e a qual, por sua vez, produz do mesmo modo determinados resultados e impactos de policy. Na fase da avaliação de políticas e da correção de ação, apreciam-se os programas já implementados no tocante a seus impactos efetivos (FREY, 2000).

É de suma importância destacar ainda o papel das instituições no processo de formulação das políticas públicas, especialmente nos debates acerca das necessidades especificas. Assim não somente os indivíduos e os grupos possuem força para influenciar o processo de formulação das políticas públicas, mas as regras tanto formais como informais das instituições, podem também exercer um papel importante no desenvolvimento de políticas públicas (SOUZA, 2006). Infelizmente, em um país como o Brasil, onde não se firmou uma democracia consolidada, o papel das instituições é frágil, com forte presença do clientelismo e do patrimonialismo na elaboração de políticas públicas (FREY, 2000).

\subsection{Políticas Públicas Educacionais}

Como vimos anteriormente, as políticas públicas podem ser definidas como aquilo que um governo faz, ou deixa de fazer. Assim, as politicas públicas educacionais podem ser classificadas, de forma análoga, como aquilo que um governo faz, ou não, pela educação.

Nos últimos anos, iniciou-se um processo de reforma nos sistemas educacionais dos países da América Latina, tomando por base as políticas sugeridas por mecanismos internacionais. Essas reformas demonstram a ineficiências dos sistemas de ensino, em relação à nova relação do Estado e sociedade (SANTOS, 2012).

Outro fato interessante é que nos últimos anos as políticas voltadas para a educação possuem ações intersetoriais, com um enfoque no transporte escolar, e em medidas que buscam a permanências dos alunos na escola, como é o exemplo das bolsas fornecidas pelo Governo Federal. 
Assim, vemos que por meio da globalização e do capitalismo iniciou-se um processo de reestruturação das políticas públicas voltadas para a educação, até mesmo pela inclusão e interferências de mecanismos internacionais, buscando otimizar os processos educacionais, atrelado à uma redução de custos em todos os processos.

Chiaro (2007, p. 104), tratando sobre essa temática, afirma que "Assim sendo, nesse contexto, as Políticas Públicas Educacionais são pensadas para adequar o Estado às políticas econômicas planejadas pelos organismos internacionais [...]". Assim, pode-se afirmar que o propulsor do desenvolvimento das políticas publicas educacionais vieram externas ao Brasil, e nosso país precisou se adequar a nova realidade mundial.

\subsection{Indicadores de Desempenho dos Gastos Públicos em Educação Básica}

É dever dos governos, utilizarem os recursos públicos no intuito de implementar políticas que proporcionem ao cidadão uma melhor qualidade de vida (NOBREGA JR., 2014).

Com o intuito de desenvolver um indicador que pudesse mensurar a qualidade na educação, o INEP (Instituto Nacional de Estudos e Pesquisas Educacionais Anísio Teixeira) criou no ano de 2007 o IDEB (Índice de Desenvolvimento da Educação Básica). Este indicador é calculado tomando por base os dados sobre a aprovação escolar, e as médias obtidas nas avaliações do INEP, que para os municípios se dá pela Prova Brasil (BRASIL, 2011).

Outros indicadores podem ser também utilizados para avaliar se os gastos com a Educação Básica estão surtindo os efeitos desejados, como é o caso das taxas de aprovação, reprovação e abandono escolar, o número de matrículas e utilização do transporte escolar, e dados sobre a infraestrutura escolar, são muito importantes para que se tenha um retrato da situação do Ensino Básico em um município ou região. Esse é o objetivo do Projeto Indicadores de Desempenho dos Gastos Públicos em Educação Básica na Paraíba, uma parceria do Tribunal de Contas do Estado da Paraíba (TCE-PB) e a Universidade Federal da Paraíba (UFPB), tal iniciativa procura construir e sistematizar indicadores educacionais, dos quais são consideradas as informações sobre o desempenho dos gastos públicos em educação no Estado da Paraíba como um todo, também por microrregiões e municípios. Dessa maneira, é disponibilizada uma vasta base de dados sobre os retornos decorrentes dos recursos públicos aplicados no setor educacional (SILVEIRA, 2012, apud TRIBUNAL DE CONTAS DO ESTADO DA PARAÍBA, 2012).

O projeto traz cinco grandes grupos de indicadores, dos quais três serão objeto de estudo da presente pesquisa. O Quadro 1 mostra os grupos de indicadores a

REUNIR: Revista de Administração, Contabilidade e Sustentabilidade ISSN: 2237-3667, Vol. 5, n. 3, p.76-92, 2015 
serem analisados, as subseções, as variáveis e suas definições, bem como as médias obtidas no ano de 2011, último ano do período de análise, para efeito de parâmetro de comparação com as médias obtidas pelo Cariri Ocidental e seus municípios.

\begin{tabular}{|c|c|c|c|}
\hline Grupo & Subseção & Variáveis & $\begin{array}{l}\text { Média - } \\
\text { PB/2011 }\end{array}$ \\
\hline \multirow{6}{*}{$\begin{array}{l}\text { Indicadores } \\
\text { de Qualidade } \\
\text { e } \\
\text { Rendimento } \\
\quad \text { Escolar }\end{array}$} & \multirow{3}{*}{$\begin{array}{l}\text { Taxas de } \\
\text { aprovação, } \\
\text { reprovação } \\
\text { e abandono } \\
\text { escolar }\end{array}$} & $\begin{array}{l}\text { Taxa de aprovação } \\
\text { Refere-se à taxa de participação dos alunos aprovados em } \\
\text { determinada fase de ensino do } \\
\text { município/microrregião/mesorregião pelo total de alunos } \\
\text { matriculados nessa mesma fase e região no ano. Fase de } \\
\text { ensino analisada: Ensino Fundamental }\left(1^{\circ} \text { ao } 9^{\circ} \text { ano). }\right.\end{array}$ & $80,99 \%$ \\
\hline & & $\begin{array}{l}\text { Taxa de reprovação } \\
\text { Refere-se à taxa de participação dos alunos reprovados } \\
\text { em determinada fase de ensino do } \\
\text { município/microrregião/mesorregião pelo total de alunos } \\
\text { matriculados nessa mesma fase e região no ano. Fase de } \\
\text { ensino analisada: Ensino Fundamental }\left(1^{\circ} \text { ao } 9^{\circ} \text { ano). }\right.\end{array}$ & $13,09 \%$ \\
\hline & & $\begin{array}{l}\text { Taxa de abandono } \\
\text { Refere-se à taxa de participação dos alunos matriculados } \\
\text { em determinada fase de ensino do } \\
\text { município/microrregião/mesorregião com registro de } \\
\text { abandono dos estudos pelo total de alunos matriculados } \\
\text { nessa mesma fase e região no ano. Fase de ensino } \\
\text { analisada: Ensino Fundamental }\left(1^{\circ} \text { ao } 9^{\circ} \text { ano). }\right.\end{array}$ & $5,92 \%$ \\
\hline & $\begin{array}{c}\text { Defasagem } \\
\text { escolar }^{2}\end{array}$ & $\begin{array}{l}\text { Taxa de distorção idade-série } \\
\text { Refere-se à razão entre os alunos matriculados em uma } \\
\text { dada fase de ensino do } \\
\text { município/microrregião/mesorregião cuja idade não } \\
\text { corresponde àquela idade adequada à sua série em } \\
\text { relação ao total de alunos matriculados nessa mesma fase } \\
\text { e região no ano. Fase de ensino analisada: Ensino } \\
\text { Fundamental }\left(1^{\circ} \text { ao } 9^{\circ} \text { ano). }\right.\end{array}$ & $36,43 \%$ \\
\hline & \multirow[t]{2}{*}{$\begin{array}{l}\text { Qualidade } \\
\text { da } \\
\text { educação }\end{array}$} & $\begin{array}{l}\text { Índice de Desenvolvimento da Educação Básica (IDEB) } \\
\text { Refere-se ao produto da média de proficiência em Língua } \\
\text { Portuguesa e Matemática (padronizada entre zero e dez) } \\
\text { para alunos concluintes das fases finais do ensino } \\
\text { fundamental ( } 5^{\circ} \text { ano e } 9^{\circ} \text { ano) pelas taxas de aprovações } \\
\text { escolares em cada fase no município no ano. Fase de } \\
\text { ensino analisada: ensino fundamental I ( } 5^{\circ} \text { ano). }\end{array}$ & 3,88 \\
\hline & & $\begin{array}{l}\text { Nota média de português } \\
\text { Refere-se à nota média de proficiência em Língua } \\
\text { Portuguesa (padronizada entre zero e dez) para alunos }\end{array}$ & 4,37 \\
\hline
\end{tabular}

\footnotetext{
${ }^{2}$ Segundo o Tribunal de Contas do Estado da Paraíba (TCE), no caso brasileiro, considera-se atualmente a idade de seis anos como adequada para ingresso no ensino fundamental, cuja duração, normalmente, é de nove anos.
}

REUNIR: Revista de Administração, Contabilidade e Sustentabilidade ISSN: 2237-3667, Vol. 5, n. 3, p.76-92, 2015 


\begin{tabular}{|c|c|c|c|}
\hline & & $\begin{array}{l}\text { concluintes da primeira fase do ensino fundamental ( } 5^{\circ} \\
\text { ano) e da segunda fase ( } 9^{\circ} \text { ano) que participaram da Prova } \\
\text { Brasil no município no ano. Fase de ensino analisada: } \\
\text { ensino fundamental I ( } 5^{\circ} \text { ano). }\end{array}$ & \\
\hline & & $\begin{array}{l}\text { Nota média de matemática } \\
\text { Refere-se à nota média de proficiência em Matemática } \\
\text { (padronizada entre zero e dez) para alunos concluintes da } \\
\text { primeira fase do ensino fundamental ( } 5^{\circ} \text { ano) e da } \\
\text { segunda fase }\left(9^{\circ} \text { ano) que participaram da Prova Brasil no }\right. \\
\text { município no ano. Fase de ensino analisada: ensino } \\
\text { fundamental I ( } 5^{\circ} \text { ano). }\end{array}$ & 4,82 \\
\hline \multirow{3}{*}{$\begin{array}{l}\text { Indicadores } \\
\text { de Matrículas } \\
\text { e Acesso à } \\
\text { Educação }\end{array}$} & \multirow{2}{*}{$\begin{array}{l}\text { Matrículas } \\
\text { por setor } \\
\text { de } \\
\text { residência }\end{array}$} & $\begin{array}{l}\text { Percentual de matrículas de residentes na zona urbana } \\
\text { Refere-se à taxa de participação dos alunos matriculados } \\
\text { na educação básica na rede de ensino do } \\
\text { município/microrregião/mesorregião que residem na zona } \\
\text { urbana em relação ao total de alunos matriculados na rede } \\
\text { de educação básica da mesma região no ano. }\end{array}$ & $48,34 \%$ \\
\hline & & $\begin{array}{l}\text { Percentual de matrículas de residentes na zona rural } \\
\text { Refere-se à taxa de participação dos alunos matriculados } \\
\text { na educação básica na rede de ensino do } \\
\text { município/microrregião/mesorregião que residem na zona } \\
\text { rural em relação ao total de alunos matriculados na rede } \\
\text { de educação básica da mesma região no ano. }\end{array}$ & $51,66 \%$ \\
\hline & $\begin{array}{l}\text { Uso de } \\
\text { transporte } \\
\text { escolar }\end{array}$ & $\begin{array}{l}\text { Percentual de matriculados que declaram usar } \\
\text { transporte escolar } \\
\text { Refere-se à taxa de participação dos alunos matriculados } \\
\text { na educação básica na rede de ensino do } \\
\text { município/microrregião/mesorregião que afirmaram usar } \\
\text { transporte escolar em relação ao total de alunos } \\
\text { matriculados na rede de educação básica da mesma região } \\
\text { no ano. }\end{array}$ & $26,52 \%$ \\
\hline \multirow{3}{*}{$\begin{array}{l}\text { Indicadores } \\
\quad \text { de } \\
\text { Infraestrutur } \\
\text { a Escolar e de } \\
\text { Docentes }\end{array}$} & \multirow{3}{*}{$\begin{array}{l}\text { Informaçõe } \\
\text { s sobre os } \\
\text { docentes }\end{array}$} & $\begin{array}{l}\text { Percentual de docentes com formação superior } \\
\text { Refere-se ao total de docentes da rede da localidade que } \\
\text { possuem formação de nível superior pelo total de } \\
\text { docentes da rede da localidade no período. }\end{array}$ & $62,21 \%$ \\
\hline & & $\begin{array}{l}\text { Percentual de docentes com ensino médio/magistério } \\
\text { completo } \\
\text { Refere-se à razão entre o total de docentes da rede da } \\
\text { localidade que têm ensino médio normal/magistério } \\
\text { completo e o total de docentes da rede da localidade no } \\
\text { período. }\end{array}$ & $26,98 \%$ \\
\hline & & $\begin{array}{l}\text { Percentual de docentes com pós-graduação } \\
\text { Refere-se à razão entre o total de docentes da rede da } \\
\text { localidade que têm pós-graduação completa (seja } \\
\text { especialização, mestrado ou doutorado) e o total de } \\
\text { docentes da rede da localidade no período. }\end{array}$ & $20,90 \%$ \\
\hline
\end{tabular}

REUNIR: Revista de Administração, Contabilidade e Sustentabilidade ISSN: 2237-3667, Vol. 5, n. 3, p.76-92, 2015 


\begin{tabular}{|c|c|l|l|}
\hline & $\begin{array}{l}\text { Índice de precariedade de infraestrutura escolar } \\
\text { Refere-se à taxa média das variáveis que sinalizam a } \\
\text { existência de problemas de infraestrutura das escolas no } \\
\text { município/microrregião/mesorregião da rede de ensino no } \\
\text { ano. As variáveis consideradas foram: se a escola funciona } \\
\text { earacterísti } \\
\text { eas } \\
\text { estruturais } \\
\text { das escolas compartilhado, se tem localização precária } \\
\text { abastecimento d'água, se não possui esgoto, se não tem } \\
\text { energia, se não tem coleta de lixo, se não existe sala para } \\
\text { diretor, se não existe sala para professores, se não existe } \\
\text { laboratório de informática, se não existe laboratório de } \\
\text { ciências, se não existe biblioteca, se não existe cozinha, se } \\
\text { não possui internet, se não oferece merenda e se não } \\
\text { existe sanitário dentro das instalações. }\end{array}$ \\
$34,92 \%$ \\
\hline
\end{tabular}

Quadro 1-Indicadores de Desempenho dos Gastos Públicos em Educação Básica na Paraíba Fonte: Tribunal de Contas do Estado da Paraíba, 2012.

Para Silveira (2012, apud TRIBUNAL DE CONTAS DO ESTADO DA PARAÍBA, 2012), a construção desses indicadores é de extrema relevância para entender alguns aspectos estruturais da educação no Estado da Paraíba, que segundo a autora, encontra-se colocado nas últimas posições em termos de qualidade da educação no país. Portanto, pretende-se, depois de analisados os dados da pesquisa, visualizar o desempenho dos indicadores de educação dos municípios do Cariri Ocidental da Paraíba de 2007 a 2011.

\section{PROCEDIMENTOS METODOLÓGICOS}

Este estudo tem a finalidade de analisar a evolução dos indicadores de desempenho dos gastos públicos em educação básica nos municípios do Cariri Ocidental da Paraíba no período de 2007 a 2011. Diante do exposto, para alcançar tal objetivo, esta pesquisa configura-se como descritiva, conduzida por meio de procedimentos documentais e abordagem quantitativa. Na visão de Gil (2009), a pesquisa descritiva tem o objetivo primordial de descrever determinada característica ou fenômeno, como também, o estabelecimento de relações entre variáveis. Outro aspecto importante diz respeito ao fato de que ela também se propõe a estudar o nível de atendimento dos órgãos públicos, o que pode perfeitamente ser relacionado ao objetivo desde estudo. Também é uma pesquisa documental, por utilizar fonte de dados primários, que conforme Andrade (2009) são

\footnotetext{
${ }^{3}$ Conforme o TCE as informações qualitativas sobre o estado da escola foram declaradas pelo diretor da escola no momento em que respondeu o questionário da prova Brasil destinado ao diretor. Este índice, quanto mais próximo de $100 \%$, pior é a situação da infraestrutura das escolas no município.
}

REUNIR: Revista de Administração, Contabilidade e Sustentabilidade ISSN: 2237-3667, Vol. 5, n. 3, p.76-92, 2015 
documentos que ainda não foram utilizados em nenhum estudo, no caso desta pesquisa foram utilizados dados do Projeto Indicadores de Desempenho dos Gastos Públicos em Educação Básica na Paraíba, através do aplicativo IDGPB Web, onde estão disponibilizados informações de vários tipos de indicadores educacionais dos municípios paraibanos, em nível municipal, microrregional e estadual dos anos de 2007 a 2011. Outra característica desta pesquisa diz respeito a sua configuração como quantitativa, ou seja, objetiva a quantificação das modalidades de coletas de dados e informações, e tem a intenção de garantir a precisão dos resultados, evitarem distorções de análise e interpretação, já que este trabalho vai analisar dados oficiais dos municípios do Cariri Ocidental da Paraíba no intuito de apresentar resultados que demonstrem a evolução do desempenho destes municípios no âmbito dos indicadores educacionais.

Quanto ao método de análise, Medeiros (2012) explica que correspondem aos procedimentos adotados para construir a interpretação dos dados. Neste trabalho foi utilizada a análise estatística descritiva que tem o objetivo de auxiliar na análise do comportamento dos dados provenientes de uma população ou de uma amostra. Para tanto, usou-se a ferramenta média aritmética, que dentro da estatística é um tipo de medida de tendência central por indicar um ponto em torno do qual se concentram os dados (GUEDES et al., 2012). Desse modo, neste estudo a partir dos resultados apresentados faz-se uma análise descritiva dos dados, descrevendo suas médias para em seguida inferir se os indicadores de desempenho estão sendo satisfatórios ou não.

A população utilizada nesta pesquisa foram dezessete municípios: Amparo, Assunção, Camalaú, Congo, Coxixola, Livramento, Monteiro, Ouro Velho, Parari, Prata, São João do Tigre, São José dos Cordeiros, São Sebastião do Umbuzeiro, Serra Branca, Sumé, Taperoá e Zabelê. Eles fazem parte da Microrregião do Cariri Ocidental do Estado da Paraíba, localizada no semiárido brasileiro, região que tem sofrido durante anos com os reflexos da seca, que impõem aos habitantes a busca por novas alternativas que possam fornecer condições para sua manutenção em seu local de origem. Nesse contexto local, desenvolver políticas que visem oferecer a população de um determinado local, a possibilidade de ter acesso a uma educação satisfatória, que favoreça o crescimento do cidadão como agente politizado capaz de promover o desenvolvimento, é muito importante para pequenos municípios. Marconi e Lakatos (2002, p. 41) definem população ou universo como "o conjunto de seres animados e inanimados que apresentam pelo menos uma característica em comum". Como as cidades continham todas as informações suficientes para análise, a amostra da pesquisa foi constituída por 100\% (cem por cento) da população. Beuren (2012, p. 120) define amostra como "uma pequena parte da população ou do universo selecionada em conformidade às regras". 


\section{RESULTADOS E DISCUSSÃO}

Com o intuito de atingir o objetivo deste estudo, foram considerados para análise dos dados, três grandes grupos de indicadores de desempenho educacional, que abarcam um total de quatorze variáveis. Como descrito no Quadro 1, os grupos de indicadores analisados foram de Qualidade e Rendimento Escolar; de Matrículas e Acesso à Educação; de Infraestrutura Escolar e de Docentes.

O Gráfico1 apresenta os resultados obtidos mediante o desempenho de três variáveis: taxa e aprovação, taxa de reprovação e taxa de abandono escolar, pertencentes a subseção Taxas de aprovação, reprovação e abandono escolar do grupo de Indicadores de Qualidade e Rendimento Escolar. Os dados são as médias do Cariri Ocidental da Paraíba de 2007 a 2011.

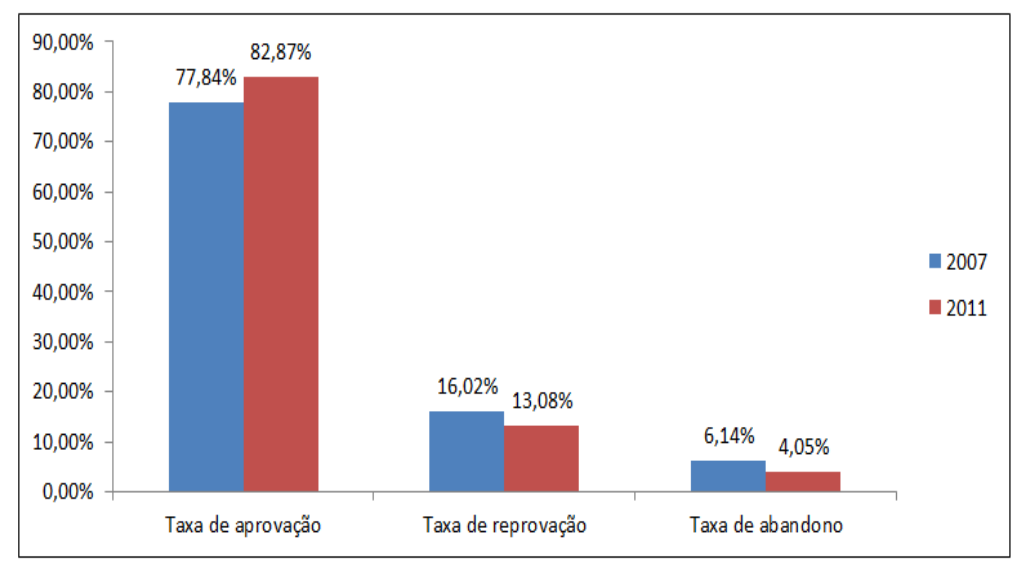

Gráfico 1 - Taxas de aprovação, reprovação e abandono escolar - Cariri Ocidental Fonte: Dados da Pesquisa, 2015.

Os resultados apresentados do Gráfico 1 mostram um efeito positivo dos indicadores em questão, haja vista o aumento das taxas de aprovação e diminuição das taxas de reprovação e abandono no Cariri Ocidental da Paraíba. A taxa de aprovação em 2007 era de 77,84\% passando para 82,87\% em 2011, representando um aumento de $6,46 \%$ dentro do período analisado. Diante desse resultado, o Cariri Ocidental fica acima da média de aprovação na rede municipal de ensino em toda Paraíba, que segundo o TCE-PB era de 80,99\%. Esses resultados apontam que a aprovação dos alunos do ensino fundamental no Cariri Ocidental são acima da média do Estado. No que se refere a taxa de reprovação, houve uma queda de 2007 a 2011 , passando de um percentual de $16,02 \%$ para $13,08 \%$, totalizando um recuo de $18,36 \%$, resultado satisfatório, refletindo o aumento nas taxas de aprovação mencionada acima. O Estado da Paraíba em 2011 teve uma taxa de reprovação de alunos do ensino fundamental de $13,09 \%$, portanto o Cariri Ocidental teve um 
desempenho melhor nesse sentido. O Gráfico 1 também aponta uma diminuição da taxa de abandono escolar na rede municipal de ensino, tendo caído 34,04\% durante o período analisado, passando de 6,14\% em 2007 para 4,05\% em 2011. Nesse aspecto também o Cariri Ocidental teve um desempenho melhor que a média da Paraíba, que em 2011 tinha uma taxa de abandono escolar de 5,92\%.

O Gráfico 2 demonstra as médias da variável taxa de distorção do Cariri Ocidental da Paraíba de 2007 a 2011, essa variável faz parte da subseção Defasagem escolar no Grupo de Indicadores de Qualidade e Rendimento Escolar.

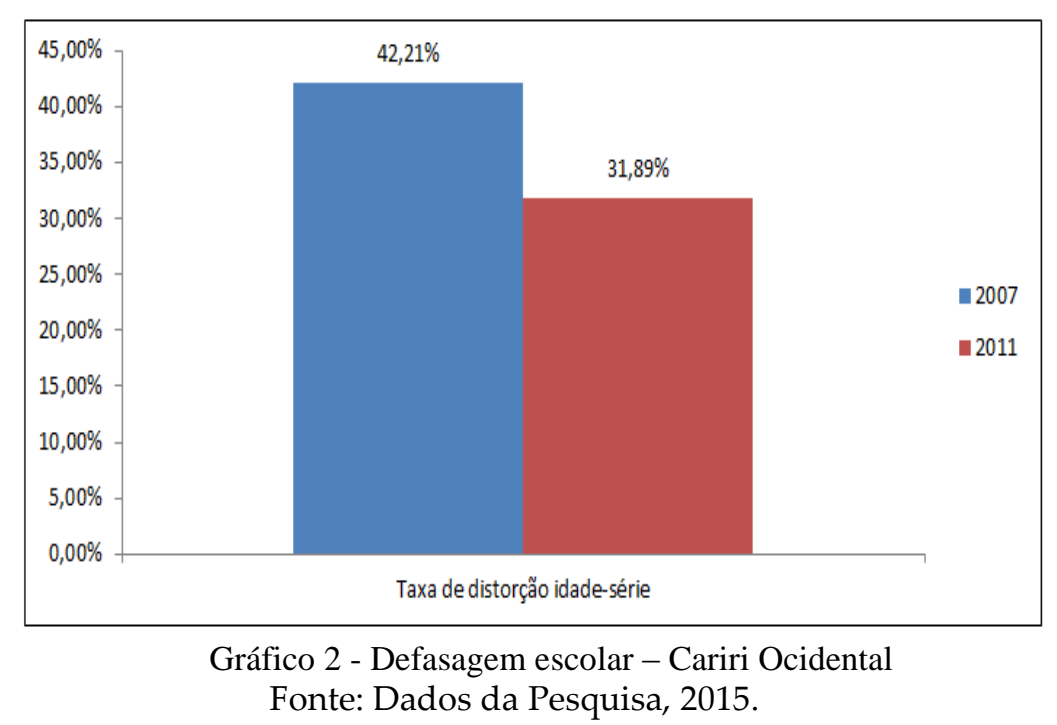

Os resultados obtidos no Gráfico 2 apontam uma diminuição na taxa de distorção idade-série. Em 2007 a média das cidades do Cariri Ocidental da Paraíba era de 42,21\% tendo recuado em 2011 para 31,89\%, uma queda em termos percentuais de 24,45\%. A média do Estado da Paraíba em 2011 era de 36,43\%. Dessa forma, mais uma vez o Cariri Ocidental apresentou resultados melhores que todo o Estado, indicando que no que se refere a aluno estudando na série certa da idade adequada, tem-se um resultado mais satisfatório que a média estadual.

Ainda dentro na análise dos indicadores do grupo de Qualidade e Rendimento Escolar, o Gráfico 3 evidencia os resultados com relação ao desempenho no quesito qualidade da educação, que englobam três variáveis: IDEB, nota média padronizada de matemática e nota media padronizada de português.

Como é demonstrado no Gráfico 3, a nota do IDEB teve uma ascensão entre os anos de 2007 a 2011, é possível ver que a nota subiu de 3,52 para 4,11, representando um aumento de 16,85\%, resultado que ficou acima da média de todo o Estado da Paraíba, que em 2011 a nota média alcançou 3,88. A nota padronizada de matemática também cresceu, em 2007 era de 4,65 passado para 4,90 em 2011, ou seja, subiu 5,45\%. 
Seguindo essa tendência positiva no indicador de qualidade escolar, a nota referente a média padronizada de português teve um crescimento de $9,65 \%$, uma vez que em 2007 sua média era de 4,13 e passou para 4,53 em 2011. Os bons desempenhos nas notas de matemática e português contribuíram para o aumento da nota do IDEB do período.

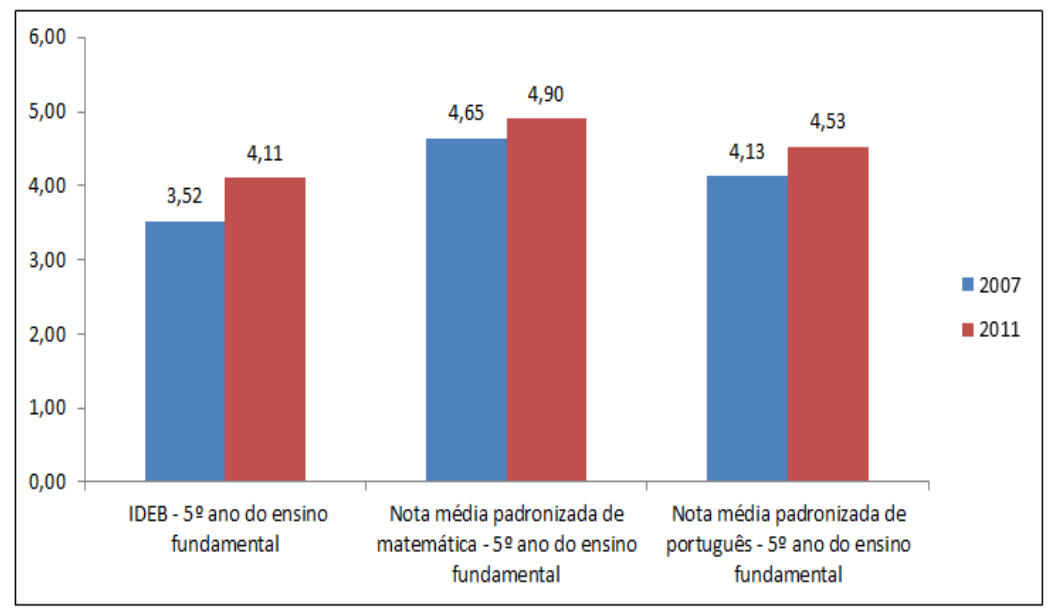

Gráfico 3 - Qualidade da educação - Cariri Ocidental Fonte: Dados da Pesquisa, 2015.

O Gráfico 4 mostra o desempenho do grupo de Indicadores de Matrículas e Acesso a Informação no período em estudo. Nesse gráfico estão agrupados duas subseções: matrículas por setor de residência, que abarcam as variáveis de percentual de matrículas de residentes na zona rural e percentual de matrículas de residentes na zona urbana; e uso de transporte escolar que agrega a variável percentual de matriculados que declaram usar transporte escolar.

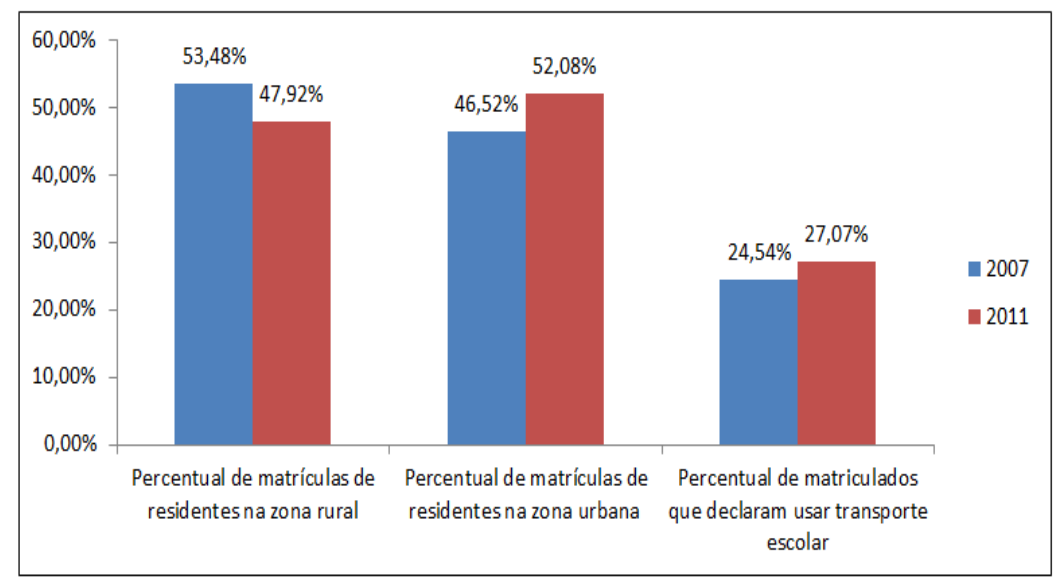

Gráfico 4 - Matrículas por setor de residência e uso de transporte escolar - Cariri Ocidental Fonte: Dados da Pesquisa, 2015.

REUNIR: Revista de Administração, Contabilidade e Sustentabilidade ISSN: 2237-3667, Vol. 5, n. 3, p.76-92, 2015 
No que se refere ao percentual de matrículas de residentes na zona rural, o Gráfico 4 mostra que houve uma diminuição do número de matrículas entre 2007 e 2011 de 10,40\%, caindo de 53,48\% para 47,92\%. O comportamento do percentual de matrículas de residentes na zona urbana teve um efeito inverso, com o aumento de 11,95\% no período, já que em 2007 esse percentual era de 46,52\%, passando em 2011 para $52,08 \%$. No que concerne ao uso de transporte escolar no Cariri Ocidental da Paraíba, 24,54\% dos alunos declaravam utilizar em 2007, já em 2011 esse número subiu para $27,07 \%$, em números percentuais representa um aumento de $10,31 \%$ de alunos que afirmavam utilizar o transporte escolar, em todo o Estado esse número era de $26,52 \%$ em 2011.

Partindo para análise dos Indicadores de Infraestrutura Escolar e de Docentes, último grupo analisado, o Gráfico 5 traz a subseção Informações sobre os docentes da rede municipal do Cariri Ocidental da Paraíba.

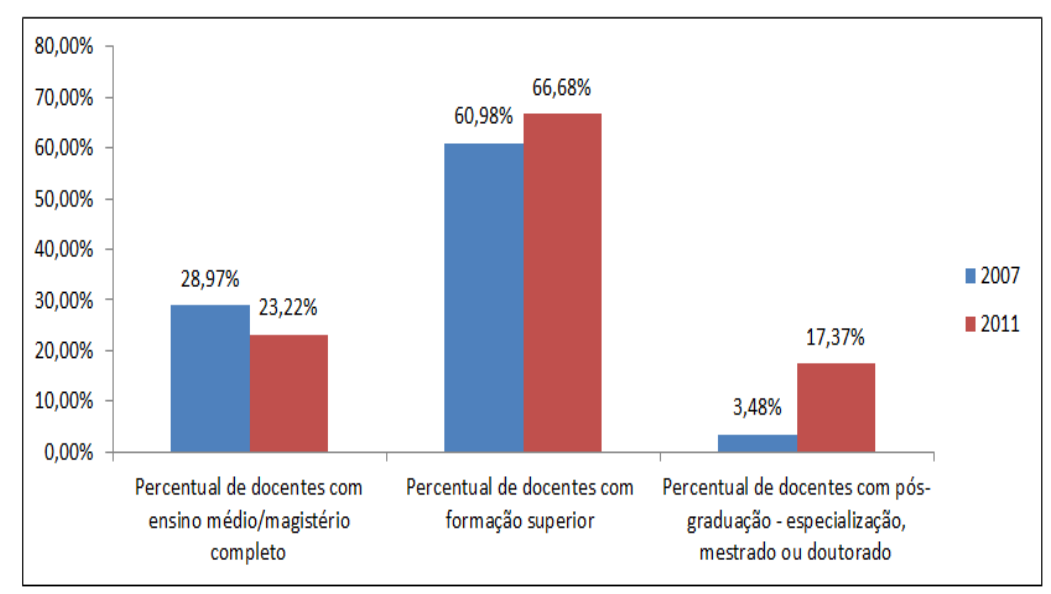

Gráfico 5 - Informacões sobre os docentes - Cariri Ocidental Fonte: Dados da Pesquisa, 2015.

No Gráfico 5 é possível visualizar as informações da formação dos docentes que atuam na rede municipal de ensino de 2007 a 2011. Os dados apontam que em 2007 o percentual de docentes com o ensino médio/magistério completo era de 28,97\% e diminuiu em 2011 para 23,22\%, representando um decréscimo de 19,86\% nos anos analisados, na Paraíba a média de docentes com esse nível de formação era de 26,98\% em 2011. Quando se consideram os percentuais de docentes com formação superior, os dados mostram que, em 2007, 60,98\% tinham curso universitário, variando positivamente em 2011 para 66,68\%, um aumento de 9,34\%, ficando acima da média da Paraíba em 2011 que era de 62,21\%. Os docentes com pós-graduação representavam em 2007 um número bastante inexpressivo de 3,48\%, contudo em 2011 esse número cresceu em 399,71\%, chegando a 17,37\%, porém abaixo da média observada em 2011 na Paraíba, que era de 20,90\%. 
Ainda dentro da análise dos Indicadores de Infraestrutura Escolar e de Docentes o Gráfico 6 apresenta o índice de precariedade de infraestrutura escolar no Cariri Ocidental da Paraíba.

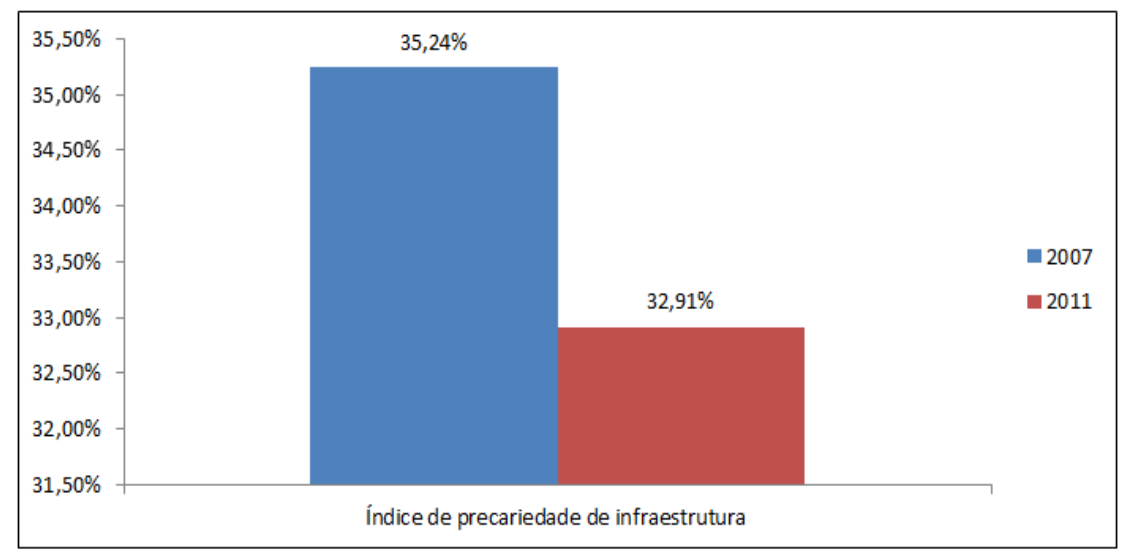

Gráfico 6 - Índice de precariedade de infraestrutura escolar - Cariri Ocidental Fonte: Dados da Pesquisa, 2015.

Como pode ser observado no gráfico acima, o índice de precariedade de infraestrutura das escolas teve um recuo de 2007 para 2011, mais precisamente em 6,60\%. Em 2007 esse índice era de 35,24\%, o que significa que a cada dez escolas do Cariri Ocidental da Paraíba, aproximadamente quatro tinham condições insatisfatórias de infraestrutura, mas no último no desta análise esse quadro apresentava melhores resultados com a queda desse índice para 32,91\%.

\section{CONSIDERAÇÕES FINAIS}

Este estudo analisou a evolução dos indicadores de desempenho dos gastos públicos em educação básica relativos a Microrregião do Cariri Ocidental da Paraíba, utilizando-se da analise estatística para tratamento dos dados e verificar sua evolução no período de 2007 a 2011.

Por meio da análise das quatorze variáveis distribuídas em quatro grupos de indicadores, que são: de Qualidade e Rendimento Escolar, Matrículas e Acesso à Educação e Infraestrutura Escolar e de Docentes foi possível perceber que o Cariri Ocidental da Paraíba evoluiu de maneira satisfatória, isso tomando como parâmetro as médias do Estado da Paraíba.

Os resultados da análise da evolução dos indicadores de Qualidade e Rendimento Escolar apontaram que houve crescimento nas taxas de aprovação, das notas do IDEB e das notas padronizadas de português e matemática, ficando todas em 2011 acima da média do Estado; outro ponto positivo verificado com relação a 
estes indicadores foi a diminuição das taxas de reprovação, de abandono escolar e de distorção idade-série, também figurando numa posição satisfatória no panorama estadual no ano de 2011.

Foi possível verificar na evolução dos indicadores de Matrículas e Acesso à Educação que houve uma mudança de 2007 para 2011 no que se refere a matrículas de residentes da zona rural para zona urbana, no primeiro ano a maioria dos alunos matriculados era habitante da zona rural com 53,48\%, no ultimo ano os alunos residentes na zona urbana já eram mais da metade com 52,08\%. Demonstrando que houve uma migração do alunado para a cidade. Diferentemente da média da Paraíba em 2011 que aponta a maioria dos alunos na zona rural. Ficou constatado que os alunos que precisam do transporte escolar para se locomover até as unidades escolares no Cariri Ocidental aumentou no período analisado nesta pesquisa, o percentual chegou em 2011 a 27,07\%, índice um pouco acima da média paraibana que foi de $26,52 \%$.

Observou-se também que os indicadores de Infraestrutura Escolar e de Docentes evoluíram de maneira satisfatória. No que concerne aos docentes, verificouse uma queda de 19,86\% no percentual de docentes com ensino médio/magistério completo e um aumento significativo em relação ao percentual de docentes com formação superior e pós-graduação, representando uma ascensão de 9,34\% e 399,71\% respectivamente, indicando uma melhora na qualidade dos professores em sala de aula na Microrregião.

Concluiu-se que no que concerne aos indicadores de desempenho dos gastos públicos em educação básica a Microrregião do Cariri Ocidental da Paraíba tende a possuir resultados acima da média do Estado da Paraíba.

\section{REFERÊNCIAS}

ANDRADE, M. M. de. Introdução à metodologia do trabalho científico. 9. ed. São Paulo: Atlas S.A., 2009.

BRASIL. Ministério da Educação. Instituto Nacional de Estudos e Pesquisas Educacionais Anísio Teixeira. IDEB - Resultados e Metas. 2011. Disponível em: <http://ideb.inep.gov.br/resultado>. Acesso em: 24 jan. 2014.

BEUREN, I. M.; et al. Como elaborar trabalhos monográficos em contabilidade: teoria e prática. 3aa ed. São Paulo: Atlas, 2012.

CHIARO, L. Estado e políticas públicas educacionais: uma análise sobre o conceito de cidadania em textos escolares após a promulgação da Constituição federal de 
1988. Curitiba, 2007. Dissertação (Dissertação em Educação). Universidade Tuiuti do Paraná. Curitiba. Disponível em: Acesso em: 20 fev. 2015.

FREY, K. Políticas Públicas: um debate conceitual e reflexões referentes à prática da análise de políticas públicas no Brasil. In: Revista Planejamento e Políticas Públicas, № 21 - Jun./2000.

GUEDES, T. A.; ACORSI, C. R. L.; MARTINS, A. B. T.; JANEIRO, V. Projeto de Ensino: Aprender Fazendo Estatística. Disponível em: $<$ http://pt.scribd.com/doc/136689180/Estatistica-Descritiva-1>. Acesso em: 04 de fevereiro. 2015.

GIL, A. C. Como elaborar projetos de pesquisa. 6. ed. São Paulo: Atlas S.A., 2009.

MACÊDO, F. R. R.; et al. Análise da eficiência dos recursos públicos direcionados à educação: estudo nos municípios do Estado do Paraná. IN: CONGRESSO BRASILEIRO DE CUSTOS, 19, 2012, Bento Gonçalves - RS: nov. 2012.

MARCONI, M. de A.; LAKATOS, E. M. Metodologia do trabalho científico. 7. ed. São Paulo: Atlas, 2009.

MEDEIROS, J. W. de M. A iniciação científica na educação a distância: a construção do conhecimento em rede. João Pessoa, 2012.

NÓBREGA JR, J. M. P. da. Políticas Públicas e Segurança Pública em Pernambuco: o case pernambucano e a redução da violência homicida. Revista Latitude, On Line, Vol. 8, no 2, pp. 315-335, 2014.

TRIBUNAL DE CONTAS DO ESTADO DA PARAÍBA. Notas Técnicas: Projeto Indicadores de Desempenho dos Gastos Públicos em Educação Básica na Paraíba, 2012. Disponível em: <http://idgpb.tce.pb.gov.br/>. Acesso em: 15 de janeiro. 2015.

SANTOS, M. A Abordagem das Políticas Públicas Educacionais Para Além da Relação Estado e Sociedade. In: Anais do IX ENPEDSUL, 2012. Disponível em: $<$ http://www.ucs.br/etc/conferencias/index.php/anpedsul/9anpedsul/paper/viewFile/ 2046/14>. Acesso em: 23 de fevereiro. 2015.

SOUZA, C. Políticas Públicas: uma revisão da literatura. In: Sociologias, Porto Alegre, no 16, jul./dez., 2006, p. 20-45. 